\title{
Ação como solução ao problema mente e corpo na teoria de Piaget ${ }^{*}$
}

\section{Action as the solution to the mind-body problem in Piaget's theory}

\author{
Jacques Vonèche** \\ Tania Stoltz ${ }^{* * *}$
}

\begin{abstract}
RESUMO
Discute-se o problema da relação entre mente e corpo na teoria de Piaget. A relação entre mente e corpo é explicada por Piaget em termos de um paralelismo entre a psique e os processos físicos. Por um lado, o corpo é uma parte integral do mundo de objetos materiais e, como tal, obedece às regras da causalidade. Por outro lado, a mente é uma unidade formal e, como tal, obedece à lei da necessidade formal que é a implicação. Qual a relação entre eles? Todas as formas de conhecimento originam-se da ação sensório-motora. Ações são primeiro somente rítmicas e depois reguladoras. Regulações dão origem a diferentes formas de comportamento de regras e consciência de normas. Essa consciência requer uma distinção entre fatos e normas, causas e significados, assim como a distinção entre corpo e mente. No entanto, os dois pólos desses pares são sempre complementares um em relação ao outro. O princípio de equilibração regula o isomorfismo potencial entre mente e corpo, como seu desenvolvimento em uma espiral geral de conhecimento. O corpo constitui o mediador entre o self e o meio, assim como essa mediação constitui, inversamente, o self ele mesmo.

Palavras-chave: mente; corpo; Piaget.
\end{abstract}

* Traduzido do original em inglês por Mônica Back. E-mail: monica.back@mps.com.br. Revisão de Tania Stoltz.

** Foi diretor dos Archives Jean Piaget da Universidade de Genebra de 1998 até 2006. Foi professor titular da Universidade de Genebra até o ano de 2005.

*** Doutora em Psicologia da Educação. Professora do Programa de Pós-Graduação em Educação da Universidade Federal do Paraná (UFPR). E-mail: tstoltz@win.psi.br 


\begin{abstract}
This article discusses the relation between mind and body in Piagetian theory. The relation between mind and body is explained by Piaget in terms of a parallelism between psyche and physical processes. On one side, the body is a part of the world of material objects and, as such, obeys the rules of causality. On the other hand, the mind is a formal unity and, as such, obeys the rule of formal necessity that is implication. What is the relation between both? All forms of knowledge have the origin in sensory-motor actions. Actions are at first rhythmic and afterwards regulatory. Regulations give origin to different forms of rule behavior and norm consciousness. This consciousness requires a distinction between facts and norms, causes and meanings, as well as the distinction between mind and body. However, both poles of these pairs are always complementary to each other. The principle of equilibration regulates the potential isomorphism between mind and body as its development in a general spiral of knowledge. The body constitutes the mediator between self and the environment, as well as this mediation inversely constitutes the self itself.
\end{abstract}

Key-words: mind; body; Piaget.

\title{
Introdução
}

Este artigo tem por objetivo demonstrar como Piaget apresentou uma solução interessante ao problema mente e corpo. No seu trabalho Introduction à l'épistémologie génétique (1950), Piaget questiona que o comprometimento com o método científico impede os psicólogos de escolher entre as soluções metafísicas clássicas para a questão mente e corpo: interacionismo, epifenomenalismo, idealismo ou monismo. Ao contrário, somente se pode asseverar um princípio de paralelismo entre a implicação mental e a causalidade fisiológica. Esse princípio não pode ser explicado exclusivamente em termos de causalidade, como ocorre no interacionismo e epifenomenalismo, ou implicação, como no idealismo e monismo.

Para Piaget, a solução se encontra na dimensão ou perspectiva genética ou do desenvolvimento. Se implicação e causação se tornam bem diferenciadas mais tarde durante o desenvolvimento, ambas têm uma origem comum: a ação. 
A ação é idêntica ao movimento para Piaget, mas movimentos que podem ser miniaturizados, internalizados e, acima de tudo, que são intencionais. Os movimentos podem ser miniaturizados em micromovimentos, como nos movimentos dos olhos, ou internalizados, como na representação. Contudo, são sempre intencionais, no sentido de que formam um mecanismo que busca a regularidade em diferentes níveis: ritmos, regulações e regras ou normas, nessa ordem de desenvolvimento. As ações são, primeiramente, somente rítmicas, e depois reguladoras. Regulações dão lugar a diferentes formas de comportamento de regras e consciência das normas.

Essa consciência acarreta uma distinção entre fatos e normas, causas e significados, tanto quanto uma distinção entre mente e corpo. Mas os dois itens sempre se complementam: não há valores sem fatos e vice-versa, nenhuma causa sem razão e nenhum corpo sem mente, da mesma forma que não há realidade sem possibilidade, objeto sem sujeito, nenhuma exteriorização sem interiorização por causa do princípio de equilibração que regula o isomorfismo potencial entre os dois opostos tanto quanto seu desenvolvimento na espiral geral do conhecimento. Conseqüentemente, a incorporação ("embodiment") torna-se central para tal perspectiva, como descrito a seguir. A incorporação é provavelmente o conceito que de modo mais claro reflete as origens fenomenológicas do pensamento de Piaget.

Na Universidade de Neuchâtel, onde Piaget foi educado, a tendência positivista era dominante na Biologia, mas não na Filosofia. Dado o interesse de Piaget por ambas, Biologia e Filosofia, ficou exposto às duas correntes de idéias no que se refere à questão mente e corpo.

Primeiramente, sua solução orientava-se pelo pragmatismo: o sistema nervoso central mantém-se informado pela periferia. Contudo, por volta dos vinte anos de idade, a influência de Bergson tornou-se dominante. Por meio dessa influência, Piaget rejeitou o realismo ingênuo da psicologia experimental e o mundo tornou-se um objeto intencional do sujeito que está a pensar sobre ele. A influência de Brentano é evidente aqui, e a escolha pelo termo intencional revela a própria convicção de Piaget.

O corpo constitui um mediador entre o self e o meio tanto quanto essa mediação constitui de modo inverso o próprio self. Isso é exatamente o que Piaget escreve com Jean de la Harpe: "experience shapes thinking as well as thinking experiencing"1 (1928, p. 33). Esse processo recíproco se encontra no ponto central da posição de Piaget na incorporação da mente, apesar de alguns leitores fazerem ligação da idéia com o empirismo, uma vez que não conseguem

1 "a experiência dá forma ao pensamento tanto quanto o pensamento à experiência". 
perceber as duas partes da sentença que claramente indicam uma ação mútua ou interação entre a experiência e o pensamento. Dessa maneira, Piaget evita tanto o idealismo quanto o empirismo a favor do construtivismo.

Para Piaget, esse processo dual de assimilação e acomodação é mediado pelo corpo, mas o corpo concebido como local da ação e, mais especificamente, dos movimentos. O que Piaget expressa por movimento, tanto quanto a maneira como analisa o movimento, merece explicações mais detalhadas.

\section{Ação como movimento e movimento como ação}

Para entender o papel central desempenhado pela ação na incorporação da mente, é necessário tomar dois exemplos da análise de Piaget: um com sua filha Lucienne e outro com ele próprio. Ambos lidam com a invenção e a representação. Lucienne tinha um ano e quatro meses de idade quando a observação ocorreu (PIAGET, 1936/1987, p. 316-318).

Obs. 179. - Um exemplo mais complexo é o da corrente de relógio que é preciso fazer penetrar num orifício de 16 x $34 \mathrm{~mm}$. Recordar-se-á, também nesse caso, as tentativas de Jacqueline (observação 173 e 173 bis). Ora, Lucienne resolveu o problema por meio de uma invenção brusca:

Ao 1; 4 (0), sem que tivesse alguma vez contemplado esse espetáculo, Lucienne olha para a caixa que eu aproximo e reviro antes que ela tenha visto o conteúdo: a corrente espalha-se no chão e ela tenta logo reintroduzi-la. Começa por meter simplesmente uma ponta da corrente na caixa e por tentar fazer o resto seguir atrás, progressivamente. Esse método, que é o empregado primeiramente por Jacqueline, é coroado de êxito com Lucienne, por acaso, logo na sua primeira tentativa (a extremidade introduzida na caixa prendeu-se aí fortuitamente); mas fracassa inteiramente na segunda e terceira tentativas.

No quarto ensaio, Lucienne começa como precedentemente, depois interrompe e, após uma breve pausa, coloca a corrente num prato vizinho (a experiência decorre em cima de um xale), fá-la numa bola, intencionalmente, agarra a bola entre os dedos e mete tudo de uma vez na caixa. 
$\mathrm{O}$ quinto ensaio começa por um retorno muito breve ao primeiro método. Mas Lucienne corrige-se imediatamente e reverte ao método correto.

Sexto ensaio: êxito imediato.

Vê-se, pois, a diferença de comportamento entre Jacqueline e Lucienne: o que na primeira era fruto de uma longa aprendizagem é bruscamente inventado pela segunda. Tal diferença é certamente uma questão de nível. Assim é que, aos 2; 6 (25), Jacqueline, com quem reato a experiência, resolve o problema sem hesitar: agarrando a corrente com as duas mãos, introduzindo-a na caixa com a mão esquerda enquanto detém com a direita a parte restante, para impedir que ela caia. No caso de se prender, ela retifica logo o movimento.

Obs. 180. - Outra intervenção elementar, resultante de uma combinação mental e não apenas de uma aprendizagem sensóriomotora, foi a que permitiu a Lucienne reencontrar um objeto dentro de uma caixa de fósforos. Com efeito, ao 1; 4 (0), isto é, imediatamente após a experiência acima, divirto-me escondendo a corrente de que acabamos de falar na mesma caixa de que nos servimos para os ensaios da obs. 170. Começo por abrir ao máximo a caixa e pôr a corrente na bainha (portanto, onde Lucienne também a introduziu, mas agora mais profundamente). Lucienne, que já se exercitou a encher e esvaziar o seu balde e diversos recipientes, apodera-se então da caixa e vira-a sem hesitar. Não se trata aqui, naturalmente, de invenção (é a mera aplicação de um esquema adquirido por tentativas); mas o conhecimento dessa conduta, em Lucienne, é útil para a compreensão do que se segue.

Depois, coloco a corrente dentro da caixa de fósforos vazia (não na bainha, mas no lugar onde se põem os próprios fósforos), mas fecho a caixa de modo a deixar apenas uma ranhura de $10 \mathrm{~mm}$. Lucienne começa por revirar tudo e, depois, tenta apanhar a corrente por aquela fenda. Não o conseguindo, introduz simplesmente o indicador na ranhura e consegue assim fazer sair um fragmento da corrente; então, puxa por ela até a solução completa.

É aqui que começa a experiência sobre a qual queremos insistir especialmente. Reponho a corrente na caixa e reduzo a fenda para $3 \mathrm{~mm}$. Fica entendido, entretanto, que Lucienne ignora o funcionamento das caixas de fósforos para fechar e abrir, e que não viu preparar a experiência. Está somente na posse dos dois 
esquemas precedentes: inverter a caixa para esvaziar o seu conteúdo e enfiar o dedo na ranhura para fazer a corrente sair. Naturalmente é este último processo que ela experimenta primeiro: introduz o dedo e tateia para localizar a corrente, mas fracassa completamente. Segue-se uma pausa, durante a qual Lucienne apresenta uma reação muito curiosa, testemunhando à maravilha não só o fato de ela tentar pensar na situação e representar para si, por uma combinação mental, as operações a executar, mas também o papel que a imitação desempenha na gênese das representações: Lucienne imita os gestos de ampliação da fenda.

De fato, ela olha para a fenda com a máxima atenção; depois, várias vezes seguidas, abre e fecha a sua própria boca, primeiro só um pouco, depois cada vez mais! Evidentemente, Lucienne compreende a existência de uma cavidade subjacente à fenda e deseja ampliar essa cavidade: o esforço de representação que ela assim forneceu exprime-se então plasticamente, isto é, não podendo pensar a situação em palavras ou imagens visuais nítidas, ela recorre, a título de "significante", ou de símbolo, a uma simples indicação motora. Ora, a reação motora que se oferece para preencher esse papel não é outra senão a própria imitação, quer dizer, precisamente, a representação em atos, aquela que, anteriormente, a toda imagem mental, sem dúvida, permite não só detalhar os espetáculos atualmente percebidos, mas, além disso, evocá-los e reproduzi-los à vontade. Lucienne, ao abrir a sua própria boca, exprime, pois, ou até, se quisermos, reflete o seu desejo de ampliar a abertura da caixa: esse esquema de imitação, com que ela está familiarizada, constitui para a criança o meio de pensar na situação. Soma-selhe, aliás, indubitavelmente, um elemento de causalidade mágicofenomenista ou de eficácia: assim como usa freqüentemente a imitação para agir sobre as pessoas e fazê-las reproduzir gestos interessantes, também é provável que o ato de abrir a boca diante da fenda da caixa implique alguma idéia subjacente de eficácia.

Logo após essa fase de reflexão plástica, Lucienne introduz sem hesitar o seu dedo na fenda e, em vez de procurar, como antes, alcançar a corrente às cegas, empurra a bainha de maneira a ampliar a abertura, o que consegue, e apossa-se da corrente.

Durante as provas seguintes (estando sempre a fenda $3 \mathrm{~mm}$ ), o mesmo processo é reencontrado imediatamente. Em compensação, Lucienne não é capaz de abrir a caixa quando esta se encontra completamente fechada: tateia, lança a caixa ao chão, etc., mas fracassa. 
A seguir a interpretação (PIAGET, 1936/1987, p. 322-324):

Retomemos, desse ponto de vista, as observações 177 a 182, comparando-as ao mecanismo da exploração empírica por tentativas. Como precedentemente, o ponto de partida dessas condutas consiste no impulso dado pelo esquema que atribui uma finalidade à ação: por exemplo, na obs. 180, a vista da corrente na caixa de fósforos deflagra o esquema de agarrar. Esse esquema de finalidade excita imediatamente certo número de esquemas que a criança vai utilizar como meios iniciais e que tratará de acomodar, isto é, de diferenciar em função da nova situação; na obs. 180. Lucienne tenta, assim, virar a caixa ou inserir um dedo na fenda para extrair a corrente da caixa. Mas, ao utilizar esses esquemas, a criança apercebe-se ao mesmo tempo das dificuldades próprias da situação que se lhe apresenta: por outras palavras, produz-se aqui, como no decorrer da exploração empírica, um reencontro com o fato imprevisto que constitui o obstáculo (a fenda é demasiado estreita para deixar o dedo passar). Ora, nos dois casos, esse reencontro acarreta uma nova intervenção dos esquemas anteriores e é graças a esses últimos que os fatos imprevistos adquirem um significado. A única diferença é que, doravante, tais encontros com o obstáculo já não se produzem no decorrer da descoberta (porquanto esta deixou de ser tateante $\mathrm{e}$ consiste agora numa invenção súbita), mas antes dela, no momento em que fracassaram os primeiros métodos experimentados a título de hipótese e em que o problema, por isso mesmo, se define. $\mathrm{Na}$ observação 180 , esses esquemas auxiliares que vêm atribuir um significado aos fatos são os que permitem à criança compreender por que a fenda que tem sob os olhos ( $=\mathrm{o}$ indício de uma abertura subjacente) e em que essa fenda é embaraçosa (porque é demasiado estreita). Com efeito, a criança chega freqüentemente a abrir e fechar caixas, querer passar a mão através de aberturas exíguas, etc. São esses esquemas que conferem um significado à situação atual e que, ao mesmo tempo, dirigem a exploração; portanto, intervêm a título de meios secundários que, por isso mesmo, se subordinam ao processo inicial. É então que intervém a invenção, sob a forma de uma acomodação brusca do conjunto desses esquemas à situação presente. Como decorre, pois, essa acomodação?

Ela consiste, como sempre, em diferenciar os esquemas precedentes em função da situação atual, mas essa diferenciação, em vez de proceder por tentativa efetiva e assimilação cumulativa, resulta de uma assimilação espontânea, logo mais rápida, que se processa mediante ensaios simplesmente representativos. Por outras palavras, em vez de explorar a fenda com o dedo e de tentar até descobrir o 
processo que consiste em puxar para si a parte interior da caixa de fósforos para ampliar a abertura, a criança contenta-se em olhar para essa abertura, fazendo incidir sua experiência não mais sobre aquela, diretamente, mas sobre os seus substitutos simbólicos: Lucienne abre e fecha a boca, enquanto examina a abertura da caixa, prova de que ela está prestes a assimilá-la e a tentar, mentalmente, a ampliação da fenda; por outra parte, a analogia assim estabelecida por assimilação entre a fenda percebida e outras aberturas simplesmente evocadas leva-a a prever que uma pressão exercida na borda da abertura a ampliará. Uma vez os esquemas assim acomodados, espontaneamente, no plano da simples assimilação mental, Lucienne passa à ação e triunfa imediatamente.

Tal interpretação aplica-se a cada uma das nossas outras observações. Na observação 179, por exemplo, se Lucienne faz uma bola com a corrente a introduzir na caixa, após ter comprovado o fracasso do método direto, é porque os esquemas adquiridos ao meter a corrente dentro de um balde ou um colar num regador (obs. 172), ou ainda ao meter uma ponta da sua almofada, do travesseiro ou de um lenço na boca, etc., lhe permitem uma assimilação suficiente da nova situação: em vez de tatear, ela combina mentalmente, portanto, as operações a executar. Mas essa experiência mental não consiste, de maneira alguma, na evocação mnemônica de imagens prontas e nítidas; é, outrossim, um processo essencialmente construtivo em que a representação nada mais é do que um ajudante simbólico, porquanto existe invenção genuína e a criança jamais percebeu uma realidade idêntica àquela que está em curso de elaboração. Nas observações 180 e 180 bis, verifica-se igualmente o funcionamento espontâneo dos esquemas de deslocamento, por analogia, sem dúvida, com as experiências que a criança pode fazer na realidade, mas essa analogia requer a imaginação de novas combinações.

Na observação 182, finalmente, vemos como um esquema inicial pode diferenciar-se, sem que seja lícito falar de exploração progressiva, por dissociação e assimilação bruscas.

Apresenta-se a seguir a observação de Piaget de si próprio como adulto (Piaget, 1936/1987, p. 324):

Para melhor compreender o mecanismo dessa assimilação que se tornou dedutiva, embora permaneça no plano das operações sensório-motoras, analisemos ainda um caso de invenção prática elementar observada no adulto e, por conseqüência, suscetível de introspecção correta. Ao conduzir um velho automóvel, sou embaraçado pelo óleo que se espalhou no volante e que o torna 
escorregadio. Não tenho tempo para parar, tiro um lenço e limpo as manchas oleosas. No momento de repor o lenço no bolso, verifico que está gorduroso demais e procuro um lugar onde escondê-lo sem que nada suje; resolvo enfiá-lo entre o meu banco e o banco vizinho, empurrando-o mais para o fundo possível nesse interstício. Uma boa hora depois, a chuva força-me a baixar o pára-brisa, mas o calor que daí resultou leva-me, entretanto, a tentar entreabri-lo. Como os parafusos estavam bastante gastos, não consigo fazer o que pretendia: o pára-brisa só se mantém todo aberto ou todo fechado. Tento agüentar com a mão esquerda o pára-brisa entreaberto, mas a fadiga leva-me a pensar que um objeto qualquer podia substituir a minha mão. Procuro à minha volta, mas nada se apresenta. Observando o pára-brisa, tenho a impressão de que se poderia entalar o objeto não na parte inferior do vidro (o pára-brisa é empurrado de baixo para cima, para abrir), mas no ângulo formado pela borda direita do pára-brisa e a empena vertical da carroceria. Tenho a impressão vaga de uma analogia entre a solução a encontrar e um problema já resolvido precedentemente. A solução define-se então: a tendência que experimento para introduzir um objeto no ângulo do pára-brisa alia-se a uma espécie de recordação motora de ter enfiado alguma coisa, há poucos instantes, numa fenda. Procuro lembrar-me do que se tratava, mas nenhuma representação nítida me acode à memória. Depois, subitamente, sem ter tido tempo de imaginar coisa alguma visivelmente, compreendo a solução e já me encontro empenhado em procurar com a mão o lenço escondido. Portanto, era este último esquema que dirigia a minha exploração há alguns momentos e que me orientava para o ângulo lateral do pára-brisa, quando a minha última idéia era diferente.

Essa observação banal mostra bem como uma pesquisa sensóriomotora pode excitar esquemas precedentes adquiridos e fazêlos funcionar independentemente da linguagem interior e da representação clara: a tendência para introduzir um objeto numa fenda vem, nesse exemplo, amoldar-se exatamente a um esquema que permanecia em estado quase puramente motor e a conjunção assim produzida basta para garantir a descoberta de uma solução. Compreende-se, pois, como uma dedução sensório-motora é possível na criança pequena por simples evocação prática dos esquemas e independentemente de um sistema bem definido de representações.

A interpretação de Piaget (1936/1987, p. 324-325):

Mas como explicar o mecanismo dessa reorganização espontânea de esquemas? Vejamos, por exemplo, a construção do esquema 
de "fazer uma bola", na observação 179, ou de "ampliar a fenda", na observação 180: essa construção consistirá numa estruturação súbita das representações ou do campo da percepção, ou será, de fato, o remate final das atividades assimiladoras anteriores à invenção? Como acabamos de recordar, certo número de esquemas já adquiridos dirige a exploração no momento em que surge a invenção, sem que nenhum deles, entretanto, contenha em si a solução correta. Por exemplo, antes de fazer uma bola com a corrente para introduzi-la no orifício estreito, Lucienne já sabia: $1 .^{\circ}$ ) comprimir um pano; $2 .^{\circ}$ ) meter a corrente em uma grande abertura; e $3 .^{\circ}$ ) comparar objetos volumosos com aberturas insuficientes (como ao querer passar vários objetos através das barras do seu parque). No caso da observação 180 , ela está igualmente na posse dos esquemas anteriores em que já insistimos. Portanto, o problema que se nos depara é o de saber como tais esquemas vão coordenarse entre si para dar origem à invenção. Será por uma estruturação independente de sua gênese ou graças à própria atividade que os engendrou e que prossegue agora sem depender mais das circunstâncias exteriores em que teve início? Isso é o mesmo que perguntar se as idéias se organizam a si próprias, no decurso de uma invenção teórica, ou se organizam em função de juízos implícitos e da atividade inteligente potencial que elas representam. Quanto a nós, não temos dúvida de que a segunda dessas duas teses é, em ambos os casos (tanto na inteligência sensório-motora como no pensamento refletido), muitíssimo mais satisfatória para o espírito, não consistindo a primeira senão num modo de falar que oculta $o$ dinamismo dos fatos sob uma linguagem estática.

Do nosso ponto de vista, algumas conclusões interessantes podem ser tiradas das observações e da interpretação de Piaget. Nas observações 179 e 180, bem como na memória de Piaget sobre o que aconteceu em seu velho carro durante um dia chuvoso, testemunham-se os mesmos movimentos corporais sugeridos espontaneamente pela situação visual.

Lucienne abre e fecha seus lábios para entender como colocar a corrente dentro da caixa. A "idéia" do corpo como um microcosmo do macrocosmo e o fato de que o que é primeiro testado no corpo pode ser estendido ao mundo dos objetos são significantes na assimilação mútua de esquemas para Piaget. Mas também indicam que o corpo está funcionando como a metáfora da realidade 
por excelência, antes e depois do aparecimento da função semiótica. O que é relevante para o propósito deste trabalho é o fato de o corpo ser, no caso de Piaget tanto quanto no de sua filha, a mãe da invenção. Ainda mais interessante é que o movimento trabalha como gatilho do comportamento inovador. Uma vez que a realidade externa é incorporada ao corpo literalmente (poderia haver uma incorporação mais perfeita?), a inovação ocorre de tal forma que parece estar-se qualificado a considerar o corpo como o workshop do pensamento ou a ferramenta da invenção. Isso se torna possível na teoria piagetiana graças ao conceito de esquema. Esse conceito, que psicólogos tendem a considerar como estritamente piagetiano ou kantiano, é, na minha opinião, pelo menos bergsoniano. Na verdade, a esquematização kantiana tem muito em comum com a de Piaget. Por exemplo, o parágrafo que começa com as palavras: "In der That liegen unsern reinen sinnlichen Begriffen ...” (KANT, 1878, p. 140-141) tem um vínculo muito piagetiano. Para os dois autores, a noção de esquema estabelece um elo entre os conceitos puros de compreensão e os objetos da experiência. Mas para Kant um esquema é simplesmente um meio para dar conteúdo ao conceito, que não é o caso para Piaget.

Considere-se agora o conceito de Bergson (1959, p. 115) de esquema motor: "So would unroll itself, in the shape of nascent muscular sensations, what we call the motoric schema of the heard word". 2 Parece muito similar com a noção de esquema de Piaget. Além disso, a influência de Bergson sobre o jovem Piaget está bem documentada pelo próprio Piaget. A citação de Bergson datada de 1896 é, provavelmente, uma reminiscência de Bergson da noção de esquema operatório de Lalande (1893), uma vez que é, de acordo com Lalande, "something like the rhythm of a verse of which one cannot find the words or like the empty motion of a press going on automatically after having printed its page".

As similaridades são bastante notáveis. Esquemas parecem ser as estruturas de um procedimento ou, pelo menos, sua forma algorítmica; são motoras na origem. Assim, o movimento é o coração da ação. Contudo, o argumento permanece de forma inversa: ação é o motor do movimento em razão de suas propriedades esquemáticas. Qualquer movimento é animado por um procedimento esquemático que se origina na sua repetição ou exercício, mas também se torna gradualmente a essência de movimentos adicionais, de tal forma que há uma reação circular entre os dois.

2 Tradução para o inglês do autor "Assim iria se desenvolver, na forma de sensações musculares nascentes, o que chamamos de esquema motor da palavra ouvida".

${ }^{3}$ Algo como o ritmo de um verso do qual não podem achar as palavras ou como o movimento inútil da prensa que continua automaticamente depois de ter imprimido a página. 


\section{Ação como a origem e forma da representação}

Até o ponto em que a ação não é somente movimento corporal, mas também intenção mental, também é a origem do movimento, pelo menos em termos de sua planificação por animais e humanos.

Seria necessário muito espaço para discutir cada modalidade sensória em detalhe, por isso analisam-se somente os movimentos dos olhos (PIAGET, 1961). Piaget não considera a percepção como um registro passivo de impressões sensórias. Pare ele, a percepção visual é resultado da atividade constante do movimento dos olhos. O que é relevante é que a percepção visual é uma forma de ação pela qual o olho e o cérebro "imitam" a forma do objeto percebido. Se for considerado, como por Piaget e Guillaume, que a imitação é sempre uma imitação do que o sujeito compreende do objeto, há uma explicação clara da ilusão e deformação visuais. Mas, além disso, há um melhor entendimento da incorporação do conhecimento; $o$ ato de perceber quantias ao escanear o campo visual, tal como o espaço aberto se torna conhecido simplesmente ao se vagar por ele. A percepção dá surgimento a constâncias e os deslocamentos espaciais à permanência.

O fato de que os movimentos dos olhos "imitam" formas e contornos indica que a passagem dos movimentos e ações sensório-motores para sua internalização como representação é, novamente, mediada pela ação corporal. Antecipando o que seria descoberto mais tarde pelos estudos eletromiográficos (KoSSLYN, 1984), Piaget propôs que as imagens mentais de uma ação eram similares à ação real e, além disso, que a simples observação de ações realizadas por outros estimulava as mesmas áreas de inervação do cérebro e do corpo com ênfase dupla sobre o componente motor e os índices espaciais mais do que os estritamente sensório-visuais.

Em termos de memória, Piaget assumiu a mesma centralidade da ação de uma estrutura de recuperação de informação de níveis superiores para os inferiores. Além disso, Piaget propôs que a posição do corpo no espaço e as diferentes lembranças de seqüências de ações realizadas durante o aprendizado aperfeiçoavam o registro e recuperação da informação e reavivavam os estados emocionais em que a aprendizagem ocorreu (especialmente um alto nível de emergência e urgência).

Piaget também argumentou que, no desenho, os movimentos envolvidos no ato gráfico desempenham o papel mais importante na representação da realidade. O que é importante para o propósito desse artigo é que o desenho como um processo motor e representativo reflete exatamente um equivalente nível mental de desenvolvimento. 
Nos conteúdos de sonhos, ações também são centrais, como em qualquer narrativa. Nas brincadeiras, o que se faz com o corpo dá significado simbólico ao objeto usual e comum que é transformado ao brincar. É porque sento na minha cadeira, virado para o encosto, e porque imito com minhas pernas o movimento para cima e para baixo de cavalgar, que a minha cadeira pode ser assimilada a um cavalo.

\section{A questão da internalização de ações}

O pensamento tem alguma relação com valores e princípios de verdade. As ações têm somente de ser eficientes. Por isso, a maioria das epistemologias filosóficas fixa o pensamento na linguagem metaforicamente ou de fato. A linguagem tem gramática, obedece a certas regras em diferentes níveis e em formas distintas: semântica, pragmática, sintática, etc. As ações parecem ser somente factuais, e não normativas. Conseqüentemente, quando Piaget fixa pensamento na ação, por meio de operações, realiza uma reversão revolucionária nas convicções comuns entre os especialistas em epistemologia, porque parece dar espaço a uma passagem do desempenho à norma. Como isso é possível?

Na verdade, todo sistema de valores é composto de duas partes diferentes. De um lado é composto de regras que são percebidas como necessárias e independentes de qualquer observação factual. De outro lado, é composto de um conjunto de dados sensório-empíricos independentes de qualquer prescrição. As ciências normativas, como a lógica e a matemática, têm valores e princípios de verdade estritamente independentes da experiência, seja teste empírico da realidade, sentimentos, crenças ou qualquer outra situação humana arbitrária. As normas são objetivas e universais.

De modo recíproco, as ciências empíricas são tão objetivas e universais como as normativas, mas seus valores e princípios de verdade recaem sobre um procedimento chamado de método experimental com base no comportamento de objetos reais. Por essa razão são chamadas de ciências experimentais.

A questão é, então, como estão essas duas formas de conhecimento relacionadas? Como a mente e o universo se juntam? As verdades experimentais, tanto quanto as constâncias físicas, dependem da observação e de medida. As verdades normativas, como a geometria n-dimensional, não podem ser compre- 
endidas com qualquer forma de experimentação física. Mas fenômenos físicos podem ser modelados por meios matemáticos. A geometria de Riemann era meramente um objeto matemático, fisicamente inútil, até que Einstein a pegou para elaborar a sua teoria da relatividade. Com base nesse modelo abstrato, várias deduções e previsões relacionadas à natureza do universo puderam ser realizadas e testadas experimentalmente pelos físicos.

Contudo, isso desloca a questão e a modifica um pouco, uma vez que significa dizer que algum tipo de acordo entre fatos e normas é possível.

Em oposição à teoria da Gestalt, nem Popper nem Piaget consideram esse tipo de harmonia entre a mente e o universo como resultado de uma lei geral da totalidade, tornando o universo isomórfico à mente e vice-versa (i.e. a idéia de que mente e universo pertencem ao mesmo sistema universal de regras físicas). Nem consideram essa harmonia como resultado de uma convenção ou acordo pragmáticos, como na concepção de democracia de Winston Churchill, "the worst of all systems, except for all the others". ${ }^{4}$ Também não aceitam o reducionismo materialista no qual essa harmonia é causada pelo simples fato de que a mente é tão material quanto o universo e, como tal, é uma mera reflexão do universo como manifestada na teoria de Lenin de empiriocriticismo ou no empirismo elementar.

O que Popper e Piaget têm em comum, apesar de suas diferenças, é uma convicção na capacidade de busca pela regra da mente humana. Essa busca estende-se desde a remota e primitiva descoberta das regularidades da natureza até as mais abstratas teorias científicas. Piaget desenvolveu sua posição em um estudo que é simplesmente intitulado ritmos, regulações e operações, os três processos cognitivos básicos (PIAGET, 1942).

Para Piaget, viver e conhecer dão continuidade um ao outro: a adaptação cognitiva é a adaptação biológica por outros meios. O equilíbrio biológico torna-se possível pelo metabolismo, a adaptação cognitiva pela auto-regulação - via os três processos básicos mencionados acima. Ritmos são as formas mais elementares de auto-regulação, como foi abundantemente demonstrado pela crono-biopsicologia, já que a alternância do dia e da noite, bem como das estações, tem fortes efeitos no relógio biológico. Mas ritmos também têm um impacto no entendimento de uma sentença na linguagem, no comportamento motor, na percepção da dor, etc.

A auto-regulação também assume duas outras formas hierarquicamente organizadas uma dentro da outra: homeostase e homeorrese. Assim, o acordo

${ }^{4} \mathrm{O}$ pior de todos os sistemas, exceto para todos os outros. 
entre fatos e normas é explicado por Piaget em termos do que K. Popper e K. Bühler chamaram de Regelbewusstsein, que é a busca por regularidades, ou melhor, o que K. Popper chama de Gesetzerlebnis, ou experiência das regras. Essa é a explicação de desenvolvimento em termos de interações entre o ser e o mundo. $\mathrm{O}$ estímulo externo é somente um estímulo se corresponder a um receptor que esteja pronto para assimilar. Em outras palavras, o estímulo é a condição material da reação do sujeito, mas o dispositivo de resposta é a condição formal para acionar a reação.

A alternância rítmica é a norma mais primitiva e a operação é a mais abstrata. Contudo, ambos aparecem no mesmo continuum de regulações. Regularidades se tornam regras quando se tornam logicamente necessárias. Assim, há passagem da causalidade para necessidade por meio das várias formas de regulações, porque a auto-regulação é nada mais do que causalidade circular por somente retroação (ou retroalimentação, feedback). Uma vez que essa causalidade circular é internalizada como um sistema abstrato de compensações, regulando-se por retroalimentação (como nos sistemas homeostáticos) ou por pro-alimentação (como na homeorrese), a integração de todas as três estruturas torna-se possível. A mente pode se mover de uma simples detecção de regularidades, que nunca são completamente reversíveis (como nas regulações), para uma reversibilidade completa, tipificada nas operações mentais. Isso somente é possível quando não há resistência do objeto, nenhum atrito, nenhum atraso, nenhuma entropia, mas reversibilidade absoluta por compensação ideal, como no pensamento. Essa liberação progressiva das condições materiais para uma estrutura absolutamente formal leva a normas puras. Mas, em qualquer nível, as normas prévias são absorvidas, como um caso especial, em normas ordenadas superiores. Esse caso especial é chamado de fato normativo (normative fact) por Piaget. Assim, a epistemologia genética estuda normas como fatos e não como tal, i.e., como norma, lei ou regra.

Um fato normativo está, por definição, sempre em mudança; é um estágio, um momento, a ser suplantado por um outro momento, um outro estado mais avançado de coisas e, como tal, historicamente contingente e, assim, relativo. Para Piaget, cada e toda norma é válida por um momento e logo será mudada por uma mais complexa, mais avançada, que constrói sua própria finalização sobre as sobras da anterior. Assim, não há verdade absoluta, todos os valores e princípios de verdade são transientes, enquanto o tipo de reestruturação essencial e automática de Husserl dá um transcendental "place of values in a world of facts", ${ }^{5}$ para usar a expressão de W. Koehler.

\footnotetext{
${ }^{5}$ Lugar de valores em um mundo de fatos.
} 
Chega-se a um ponto muito difícil: se toda verdade é verdadeira de forma passageira (en passant), deve necessariamente haver uma verdade perene (Veritas perennis) como ponto de partida para julgar isso. Em outras palavras, a veracidade do relativismo deve estar baseada, no fim, em algum tipo de absoluto para ser verdade. Esse é o paradoxo do relativismo absoluto. É o paradoxo teórico de Piaget. É, mais geralmente, o paradoxo de toda forma de estruturalismo genético. É a combinação desses dois aspectos que levanta a questão. Ou se toma a perspectiva do estruturalismo e se presume que cada estrutura é um tipo de mônada de si mesma e, como tal, deveria ser julgada de qualquer ponto de vista externo, ou se adota a perspectiva genética, a partir da qual qualquer novidade em desenvolvimento é considerada como mais avançada, hierarquicamente superior e mais madura do que os estágios anteriores de desenvolvimento. Mas essa avaliação deve necessariamente ser realizada de um ponto de vista externo, provendo um princípio ortogenético ou invariante, do qual critérios para o desenvolvimento, avanço e evolução são dedutíveis. Retirar-se para critérios empíricos externos é falacioso. Com freqüência, na psicologia do desenvolvimento, o critério de tempo foi usado como um princípio de ordenação, mas leva à conclusão errônea de que qualquer coisa que apareça mais tarde é necessariamente mais avançada: o recente é confundido com progresso.

Piaget recorreu a um princípio que considerava ainda imanente, mas, além disso, orientado para a finalidade (telos-oriented): a equilibração majorante. Equilibração é, por definição, imanente ao sistema considerado. Contudo, uma vez que Piaget finalmente declara que toda equilibração se torna majorante, ele realmente quer dizer que o sistema constantemente otimiza seu equilíbrio com a passagem do tempo. É uma posição perigosa de se manter, porque não há razão interna ao próprio sistema que motive essa mudança direcional. Desse modo, Piaget está, na realidade, usando um argumento que admite como provado para a questão que quer provar.

Ao se observar a relação entre ação e valores, confronta-se com outra variante da mesma dificuldade: não há continuidade entre os dois, e agora esta é reconhecida por Piaget sob a forma de uma dualidade entre ação causal e pensamento significante sob a forma de paralelismo psicofísico, como será examinado a seguir. 


\section{O problema corpo e mente}

A relação entre corpo e mente é explicada por Piaget em termos de um paralelismo entre a psique e os processos físicos. De um lado, o corpo é uma parte integral do mundo de objetos materiais e, como tal, se submete à regra da causalidade. Por outro lado, a mente é uma unidade formal e, como tal, obedece à lei da necessidade formal que é a implicação. Assim, corpo e mente parecem pertencer a dois universos diferentes do discurso: causalidade material e implicação formal. Eventos que acontecem no corpo são explicados pela causalidade, eventos mentais por necessidade lógica ou implicação. Assim, parece haver dois sistemas paralelos governados por duas regras diferentes. Então, qual é a relação entre eles?

Para Piaget, há duas séries de eventos: os materiais e os mentais, co-ocorrendo e sendo explicados por termos diferentes (causalidade e implicação). Durante o curso da ação, qualquer ato humano é intencional, proposital e significativo. É comandado pela lógica dos significados. Uma explicação causal da ação humana se torna possível somente a posteriori, assim que o curso da ação está explicitamente terminado, por oposição a uma explicação formal que antecipa a ação considerada como um comportamento direcionado pelo objetivo.

Tal posição é, de certa forma, surpreendente, uma vez que supõe dois fatos que não são óbvios no pensamento de Piaget: o primeiro é a suposição do dualismo no sentido mais clássico, que não parece congruente com a idéia de continuidade entre biologia e psicologia ou entre processos fisiológicos e cognitivos, que também é característico da teoria de Piaget. A segunda origina-se da primeira: se há um paralelismo psicofísico, como Piaget reconcilia essa idéia com aquela de uma continuidade da biologia para a psicologia? Deve haver, tanto lógica quanto geneticamente, um momento em que a concatenação causal se torna implicação lógica. Portanto, deveria haver uma razão para essa transformação.

Infelizmente, nenhuma razão é encontrada nos escritos de Piaget, como se o paralelismo não originasse nenhuma pergunta dentro de sua perspectiva. A passagem acontece durante a filogenia, uma vez que não aparece durante a ontogenia? Não há nenhuma sugestão para isso também. A única maneira como Piaget lida com o problema é presumindo que operações mentais transformam idéias da mesma maneira que as ações transformam objetos ou, mais precisamente, coisas no mundo físico. Acertado, mas, novamente, supõe a pré-existência do paralelismo. Aúnica luz sobre a gênese do paralelismo vem dos escritos de Piaget (1967, p. 26) sobre biologia em que mostra como a adaptação cognitiva continua a adaptação biológica. 
Cognitive processes seem, then, to be at one and the same time the outcome of organic autoregulation, reflecting its essential mechanisms, and the most highly differentiated organs of this regulation at the core of interactions with the environment, so much so that, in the case of man, these processes are being extended to the universe itself. 6

Mas essa declaração, por sua vez, traz um grande número de perguntas. Primeiro, considerar os processos cognitivos como órgãos apresenta um elo com o idealismo no sentido de que tal declaração concede um status de realidade material às idéias e, como tal, funde materialidade com idealidade e dá a questão do paralelismo como provada. Segundo, no caso de se prosseguir com a analogia mais adiante, como podem processos se tornar estruturas, já que órgãos são estruturas por definição? Os processos se encontram no lado genético, do desenvolvimento das coisas. Órgãos estão no lado estrutural. Já se reparou que há certo desacordo de sistemas entre essas duas noções. Dessa maneira, a analogia parece imprecisa em cada aspecto e confunde, em vez de ajudar.

Uma segunda leitura da passagem acima e da seguinte pode elucidar o que Piaget (1967, p. 34) expressa nesse contexto:

Cognitive autoregulation makes use of the general systems of organic regulation such as are found at every genetic, morphogenetic, physiological, and nervous level, and forthwith adapts them to their new situation [...] This situation constitutes the exchanges with the environment that form the basis of behavior. ${ }^{7}$

Conseqüentemente, isso significa que não se pode dizer que a cognição ocorra em nenhum dos sistemas orgânicos do corpo convencionalmente definidos, mas se desenvolve para além deles e os reorganiza em um novo conjunto de relações funcionais. Essa reorganização leva a algumas diferenças

\footnotetext{
${ }^{6}$ Processos cognitivos parecem ser, então, a um e mesmo tempo, o resultado da auto-regulação orgânica, refletindo seus mecanismos essenciais, e parecem ser os órgãos mais diferenciados dessa regulação no centro das interações com o ambiente, tanto que, no caso do homem, esses processos são estendidos ao próprio universo.

${ }^{7}$ A auto-regulação cognitiva faz uso de sistemas gerais de regulação orgânica tais como encontrados em cada nível genético, morfogenético, fisiológico e nervoso e imediatamente os adapta a sua nova situação [...] Essa situação compõe as trocas com o ambiente que formam a base do comportamento.
} 


\section{importantes entre o funcionamento orgânico e o cognitivo. As mais cruciais são completude, estabilidade e flexibilidade das estruturas cognitivas comparadas às orgânicas, como apresentado na passagem a seguir.}

Here, then, is the conclusion of this summary of our guiding hypotheses. The living organization is an equilibrated system (even if one avoids the term and substitutes Bertalanffy's "stable states in an open system"). But this organic equilibrium only represents a relative sort of stability in those very fields where it is best protected. The genome is isolated to the maximum degree from its environment, although it cannot be so completely; its equilibrium is nevertheless upset by mutations, etc., despite these ideal conditions. The epigenetic system is more open, but it finds its equilibrium by means of a number of processes, among them homeorrhesis. Physiological systems are even more "open", and yet they react by homeostasis of the interior environment - an environment all the more remarkably stable as the various animal groups are evolved and differentiated. The role of the nervous system is to be open to external stimuli and to react to them by means of its effectors; its increasing mobility does not prevent there being remarkably mobile equilibrium in the overall reactions. Finally, behavior is at the mercy of every possible disequilibrating factor, since it is always dependent on an environment which has no fixed limits and is constantly fluctuating. Thus, the autoregulatory function of the cognitive mechanisms produces the most highly stabilized equilibrium forms found in any living creature, namely, the structures of the intelligence, whose logico-mathematical operations have been of inescapable importance ever since human civilization reached the stage of being consciously aware of them ${ }^{8}$ (PIAGET, 1971, p. 36-37).

${ }^{8}$ Apresenta-se aqui a conclusão desse resumo das hipóteses orientadoras. A organização de vida é um sistema equilibrado (mesmo no caso em que se queira evitar o termo e substituílo pelo de Bertalanffy, "estados estáveis em um sistema aberto"). Mas esse equilíbrio orgânico somente representa uma espécie relativa de estabilidade naqueles mesmos campos em que está mais bem protegido. O genoma está isolado de seu ambiente em grau máximo, apesar de não poder ser assim completamente; seu equilíbrio é, não obstante, perturbado pelas mutações, etc. apesar dessas condições ideais. O sistema epigenético é mais aberto, mas encontra seu equilíbrio por meio de um número de processos, entre eles a homeorrese. Os sistemas fisiológicos são ainda mais "abertos" e, contudo, reagem pela homeostase do ambiente interno - um ambiente ainda mais notavelmente estável à medida que os vários grupos de animais evoluem e se diferenciam. O papel do sistema nervoso é estar aberto aos estímulos exteriores e reagir a eles por meio de seus efetores; sua mobilidade crescente não impede o equilíbrio móvel notável nas reações totais. Finalmente, o comportamento está à mercê de cada fator possível de desequilíbrio, uma vez que é sempre dependente de um ambiente que não tem limites fixos e está em constante oscilação. Desse modo, a função auto-reguladora dos mecanismos cognitivos produz as formas de equilíbrio mais estabilizadas encontradas em qualquer criatura viva, a saber, as estruturas de inteligência, cujas operações lógico-matemáticas têm sido de importância capital desde que a civilização humana alcançou o estágio de estar consciente delas. 
Outra diferença deve ser aqui mencionada: "the outstanding characteristic of cognitive organization is the progressive dissociation of form and content" (Piaget, 1971, p. 153).

O assunto se torna ainda mais complicado com a introdução da dimensão social na cognição. Até 1928, Piaget costumava considerar que interações com os outros auxiliavam a criança a sair do egocentricismo e entrar na descentração (isso quer dizer considerar o self como parte do mundo em vez de seu centro). Mas, na reunião anual da French Philosophical Society em 1928, o francês, psicólogo do desenvolvimento, Henri Wallon (apud PiAget, 1928, p. 133), nos seus comentários sobre o ensaio de Piaget, lhe disse:

instead of making of sociability the agent and the factor of relational thinking, I would reverse the terms, I would say that, when, due to organic development, the child has become capable of holding together two different points of view, that is to say capable of those (extremely complicated) mental operations consisting of retaining from a given situation only certain elements, in other words of inhibiting, somehow, the representation of everything else, so that the child can constitute systems of relationships that are no longer those continuous wholes, those dynamic situations from which the child started, then (and only then) could his sociability be transformed into relational thought. ${ }^{10}$

A discussão com Wallon demarca uma importante reversão no pensamento de Piaget. Depois dessa conferência de 1928, Piaget começou a pensar no desenvolvimento mental como o fator causal da socialização e não mais o oposto. Contudo, nesse meio tempo, inclinou-se para a abordagem empirista de acordo com a qual o ambiente sociocultural é a causa do desenvolvimento mental. Como Wallon (apud Piaget, 1928, p. 136) disse no final da discussão:

${ }^{9}$ A característica marcante da organização cognitiva é a dissociação progressiva da forma e do conteúdo.

${ }^{10} \mathrm{Em}$ vez de fazer da sociabilidade o agente e fator do pensamento relacional, eu reverteria os termos e diria que quando, por causa do desenvolvimento orgânico, a criança tornou-se capaz de manter juntos dois pontos de vista diferentes, isso quer dizer, capaz dessas operações mentais (extremamente complicadas) que consistem em conservar, de uma dada situação, somente certos elementos, em outras palavras, de inibir, de alguma maneira, a representação de todo o resto, de tal forma que a criança pode constituir sistemas de relações que não são mais aqueles conjuntos contínuos, aquelas situações dinâmicas de onde a criança começou, então (e somente então) pode sua sociabilidade ser transformada em pensamento relacional. 
"instead of explaining the emergence of our logic (adult logic) in the child by a progress in sociability, I would explain sociability by advances in mental abilities", ${ }^{11}$ o que é uma perspectiva racionalista genética que Piaget desenvolveu nos anos 1940 e 1950.

Como demonstrado, a posição de Piaget sobre a questão corpo e mente é muito confusa até o último capítulo do primeiro volume "History and methods" do seu Traité de psychologie expérimentale editado em conjunto com Paul Fraisse, em que apresenta sua própria versão do paralelismo psicofísico, que é muito bom, mas não é coerente com sua visão geral das relações entre os processos mentais cognitivos e a adaptação orgânica. O lugar da mente não é nem na sociedade, como na posição de Vygotsky, nem no corpo, como na maioria das teorias psicológicas para as quais a mente e o cérebro são um e o mesmo. Há somente uma transformação na coordenação dos órgãos, como, por exemplo, para diferenciar a forma do conteúdo que emerge gradualmente de várias formas cada vez mais abertas de equilíbrio entre o organismo e seu ambiente. Poder-se-ia esperar algo mais do que simplesmente paralelismo e níveis de consciência dentro de um sistema de equilíbrio cada vez mais móvel que termina em estruturas mentais mais abstratas e estáveis, a saber, as famosas estruturas lógico-matemáticas.

$\mathrm{O}$ aparecimento dessas estruturas mentais poderia ser resumido em três pontos:

1. há três níveis de consciência;

2. há um movimento do sucesso prático para a compreensão conceitual;

3. existe um paralelismo psicofísico.

Os três níveis de consciência se distinguem à medida que o sujeito se torna consciente de seu próprio funcionamento. O primeiro nível, ou consciência prática, aparece no período sensório-motor e é irreflexivo. É a mera percepção de sucesso ou fracasso de uma ação (coordenação de meios e fins). O segundo nível (que é característico do período de operações concretas) pode ser definido como consciência conceitual. É uma forma de reflexão que aumenta a mobilidade e reversibilidade da inteligência. O terceiro nível marca a passagem para a consciência reflexiva, que quer dizer não somente a capacidade de coordenar, mas também aquela de tomar seu próprio funcionamento como um objeto de consciência, que é a operação sobre a operação. Isso somente pode ser realizado com o advento de operações formais.

O movimento do resultado prático para a compreensão conceitual é necessário, dentro do sistema de Piaget, para explicar a distinção entre inte-

${ }^{11}$ Em vez de explicar o surgimento de nossa lógica (de adulto) na criança com um progresso na sociabilidade, eu explicaria a sociabilidade pelos avanços nas habilidades mentais. 
ligência prática, que visa somente ao resultado, e inteligência conceitual, que visa à compreensão. Para Piaget, a inteligência prática se desenvolve antes da conceitual e forma uma condição necessária para a inteligência conceitual, mas permanece atrás na compreensão do resultado porque sua consciência é mais direcionada ao objeto externo do que ao mecanismo interno. Portanto, a tomada de consciência inverte a ordem da construção e é um subproduto tardio das operações formais e suas reversibilidades e reflexibilidades completas. Como tal está necessariamente baseada: 1) em uma diferenciação de forma e conteúdo e 2) em uma antecipação aumentada dos estados de coisa possíveis por causa da otimização do princípio de equilibração.

\section{O corpo tornado mente}

O longo desvio pela questão corpo e mente e a questão de consciência era necessário para entender como, para Piaget, a passagem da ação para o pensamento se torna possível. É o efeito secundário da distinção entre meios e fins no nível sensório-motor. Essa verdadeiramente primeira forma de consciência determina a passagem da ação para pensamento de maneiras diferentes: 1) a fixação de valores e princípios de verdade; 2) a internalização de ações em símbolos pela imitação mental; 3) as imagens mentais; 4) a noção de self como "corps propre" (distinção de Körper e Leib na língua alemã adaptada para o francês, "corpo próprio").

A fixação de valores e princípios de verdade às ações se torna possível pela típica distinção entre meios e fins do primeiro nível de consciência. Esse nível prático de consciência é marcado pela consciência do sucesso e fracasso de uma ação, por um lado, e pela constituição de invariantes funcionais de outro lado. Isso quer dizer que a criança é capaz de hipóteses de mundo permitindo distinções tais como as que separam o mesmo objeto, visto duas vezes (repetição), de dois objetos similares, cada um visto uma vez (equivalência). Tais invariantes podem ser consideradas como inatas, aprendidas ou construídas. Se fossem inatas, seriam acionadas por um estímulo externo durante o período de sensitividade a esse estímulo (como no caso do peixe macho esgana-gato (Gasterosteus aculeatus) durante a estação de desova), apropriadamente chamado de período crítico, que seria internamente determinado. Observações reais tendem a demonstrar que esse nunca é o caso no desenvolvimento mental.

Se fossem aprendidas, aquelas invariantes apareceriam de acordo com um programa de reforçamento e exercícios. Isso ainda não foi demonstrado e não 
está de acordo com a lógica progredindo do simples ao mais complexo, tal como parece acontecer. Um movimento da simplicidade à complexidade seria a melhor evidência a favor da construção lógica, porque ir do simples ao complexo é, na verdade, lógico, além de ser uma construção, porque algo é simples ou complexo relativamente a um sujeito. $\mathrm{O}$ fato de que algo é simples para o sujeito significa que algo mobiliza imediatamente recursos e conhecimento disponíveis no sujeito sem esforço, enquanto algo complexo requer muito mais recursos e conhecimento tanto quantitativa quanto qualitativamente, quer dizer, estruturas mais elaboradas. Também significa que (em termos de desenvolvimento) a construção é lógica em vez de genética (como na motivação) ou ambiental (como na aprendizagem). Isso igualmente quer dizer que aparentemente formas mais avançadas de raciocínio e pensamento supõem, somente logicamente, prévias formas menos complexas e não supõem, na verdade, uma forma fisicamente verificada de ordem hierárquica inferior do que a mais complexa. Essa argumentação lógica cuida do "elo perdido" (missing link) da biologia ou da "tribo perdida" (lost tribe) da sociologia. Na lógica, todos os elos e articulações deveriam estar presentes.

De acordo com essa hipótese, universais não são nem a expressão de uma estrutura inata nem o reforçamento de uma seqüência empírica, mas o resultado de uma coordenação crescente de ações não somente como presenciado na contagem, mas também quanto ao outro aspecto de dar significado ao espaço e tempo, classes e séries, causalidade e implicação. A permanência do objeto é o resultado prático do grupo de deslocamento, representando uma coordenação complexa de movimentos do self (corpo), do objeto e dos anteparos que cobrem o objeto com suas conseqüências asseguradas. Também requer a distinção entre movimentos corporais tornados significantes como "self action" e os movimentos dos objetos.

Assim, o desenvolvimento simbólico consiste na construção realizada pela criança de sistemas de procedimentos mais consistentes e mais completos para transformar a significação sensório-motora em operações simbólicas. Essa transformação consiste na internalização gradual de ações corporais. Mas o corpo, nesse caso, é o que a língua alemã chama de Leib, em oposição a Körper. Leib é o corpo animado pelo self, enquanto Körper é o corpo externo objetivo. Uma vez que essa distinção não existe em língua francesa, que apresenta somente uma palavra, corps, Piaget (como outros) chama esse corpo "interno" de corps propre (corpo próprio). Dada a simetria do corpo humano tanto na ação sensória (dois olhos, dois ouvidos) como motora (dois braços, duas pernas, duas mãos), os universais humanos tendem a depender das estruturas simétricas de pensamento, como no caso da reversibilidade no nível mais abstrato. Esse não é o momento para demorar-se nesses eixos de simetria tanto bilateral quanto vertical, como evidenciado pela oposição entre 
cabeça e pés, com a cintura como o ponto central desse eixo. Mas deveria ser observado que nossos universais seriam provavelmente completamente diferentes se tivéssemos corpos diferentes.

Contudo, o importante é observar, na formação simbólica como descrita acima, o fato de que os símbolos são o produto da relação entre as ações autoreguladas e o objeto físico. A ação providencia a predicação. Esse processo é o lado semântico da lógica da ação e dá razões satisfatórias para as surpresas. Uma criança fica surpresa quando o mundo não se comporta de acordo com suas expectativas. Há um número de regulações e operações rítmicas que são esperadas de um ambiente significativo predicado como um objeto único. Contudo, também há muitos procedimentos disponíveis para a criança testar as hipóteses levantadas sobre o ambiente, tais como remover o anteparo, contar, etc. A ação não é mais somente eficiente, torna-se informativa. Essa informação é, por sua vez, codificada em símbolos, imagens mentais, etc. Mas deve ficar registrado que cada um desses símbolos representa uma transformação de um estado prévio de um tipo de álgebra booliana de opostos: alto é o oposto de baixo no aspecto figurativo ${ }^{12}$ das coisas, tal como ficar em pé é o oposto de deitar no aspecto operativo. ${ }^{13}$ Deve-se lembrar que figuratividade é a sedimentação das formas anteriores de operatividade que se tornaram automatizadas. Em cada caso, contudo, o corps propre (corpo próprio) desempenha o essencial de um padrão de acordo com tudo que é medido. Portanto, o pensamento, no final, significa o corpo tornado mente.

Nessa perspectiva, o corpo desempenha o papel central, uma vez que é o lugar em que a mente é articulada com o ambiente. $O$ corpo é parte do ambiente ou do mundo, mas é também o lugar onde a mente vem ao mundo. Isso pode ser apresentado sob o prisma do desenvolvimento, uma vez que, primeiramente, o bebê vive em um estado de adualismo, como primeiro notou J. M. Baldwin (1895). O self e os outros, o self e o mundo são um, sem fronteiras ou limites. Então, o corpo torna-se o modelo de todas as ações e capaz de todas as ações sobre o ambiente por meio de diferenciação progressiva. Mais tarde, aparece a distinção entre a esfera real da ação do corpo sobre o ambiente com a arti-

12 Conhecimento figurativo - conhecimento que enfoca o aspecto externo figural de um evento de uma maneira estática, estreitamente ligado a uma acomodação particular e como ilustrado na percepção, imitação, imagem, memória. O conhecimento figurativo somente é concebível dentro de uma estrutura de conhecimento operativo.

13 Operatividade - Contrastado com o conhecimento figurativo, indica o aspecto da ação da inteligência em todos os períodos, incluindo a inteligência sensório-motora. A operatividade é o aspecto essencial, generalizável e estrutural da inteligência, a tal grau que o conhecer significa construir, transformar, incorporar, etc. 
culação de meios com os fins no nível prático. Com a formação de símbolos, o aprofundamento da lacuna entre o self e seu mundo interno e a realidade externa se torna qualitativamente diferente: por representação, a criança entra no mundo do faz-de-conta, dos contos, sonhos, brincadeiras, desenhos e da imitação que todos fazem presentes na mente quando ausentes da realidade. Seguindo a mesma linha de raciocínio, a autoconsciência se torna possível e esse é o ponto de partida da reflexão que será tão importante para os desenvolvimentos futuros, porque é por meio dessa auto-reverberação que cada passo adiante na direção da realidade externa se torna, ao mesmo tempo, um passo adiante na direção do self interno, como demonstrado nos escritos de Piaget no último capítulo dos volumes: Origins of intelligence (PIAGET, 1952) e The construction of reality (PIAGET, 1955).

Contudo, nesse processo de assimilação e acomodação complementar, realidade e self se tornam cada vez mais diferenciados no aspecto em que a acomodação não mais permanece na superfície da experiência, mas, em vez disso, penetra cada vez mais dentro da estrutura interna da matéria, procurando por regularidades sob o caos da experiência. E aquela assimilação, em vez de permanecer egocêntrica, procura incorporar fenômenos externos às estruturas internas e mais íntimas da inteligência, isso quer dizer, um sistema arbitrário dedutível de sinais cujo significado foi dado durante a evolução (tanto ontogenética quanto filogenética) na co-ação e co-operação com outros usuários de sinais e intercambiadores.

Como se pode observar, tal posição está muito distante de posições como “The synaptic self” (O ser sináptico), de Joseph Le Doux (2002), de acordo com o qual a pessoa é o que as sinapses dizem para ela ser ou, ainda, como da psicologia computacional, para a qual o paralelismo psicofísico é equivalente à divisão de software e hardware dos computadores. Entretanto, é também diferente da tradição vygotskiana. A posição de Piaget inclui tanto a dimensão social das produções corpóreas (incluindo a linguagem) como a biológica, enquanto a abordagem vygotskiana unicamente explica a internalização do valor comunicativo dos sinais lingüísticos, e não o fato de que a sociedade e a cultura são as continuações (por outros meios, certamente) de espécies e da natureza. Na visão vygotskiana (1987), assim como na de Saussure (1972), a arbitrariedade de sinais os torna radicalmente diferentes da natureza.

Ao contrário, a abordagem de Piaget, pelo seu enfoque na origem sensório-motora de todas as formas de conhecimento e sua gradual transformação em índices, símbolos e sinais a partir da mera implicação sensório-motora inicial envolvida na ação, demonstra, sem nenhuma dúvida, a existência de uma origem direta da ação ao conceito (por meio da representação e do 
funcionamento semiótico) por um processo duplo de abstração reflexiva e equilibração majorante. Essa equilibração se torna possível por um processo duplo de transformação: equilibração propriamente dita, ou o primeiro mecanismo transicional, e o mecanismo intra-inter-trans de transição, ou segundo mecanismo, como explicado a seguir (PIAGET, 1983). No primeiro momento, o crescimento do conhecimento vai (a) da reequilibração após a perturbação para a (b) reequilibração por integração da perturbação e (c) reequilibração por antecipação de variações possíveis. No segundo processo, segue do intraobjetal para inter-objetal e trans-objetal. Assim, vai do conhecimento no curso da ação corpórea (análise do objeto sensório-motor) para as inter-relações entre a ação presente e aquela representada (relações e transformações semióticas) para terminar nas trans-relações no nível mais abstrato ou estruturas-mãe do conhecimento (estruturas formais).

Assim, espera-se ter apresentado um novo olhar ao complexo problema filosófico, e aqui, sobretudo cognitivo, das relações entre mente e corpo.

\section{REFERÊNCIAS}

BALDWIN, J. M. Mental development in the child and the race. New York: McMillan, 1895.

BERGSON, H. Matter and memory. Oeuvres. Ed. du Centenaire. Paris: Presses universitaires de France, 1959.

HUSSERL, E. Prolegomena zur reinen Logik. Halle: Niemeyer, 1913.

KANT, I. Kritik der reinen Vernunft. Leipzig: Reclam, 1878.

KOHLER, W. The place of value in a world of facts. New York: Liveright, 1938.

KOSSLYN, A. Image and brain: the resolution of the imagery debate. Cambridge Mass: M.I.T. Press, 1994.

LALANDE, A. Lectures sur la philosophie des sciences. Paris: Alcan, 1813.

LE DOUX, J. E. Synaptic self: how our brains become who we are. New York: Viking, 2002. 
PIAGET, J. Les trois systèmes de la pensée de l'enfant: étude sur les rapports de la pensée rationnelle et de l'intelligence motrice. Bulletin de la Société Française de Philosophie, v. 28, n. 4, p. 97-141, 1928.

. Les trois structures fondamentales de la vie psychique: rythme, regulation et groupement. Revue Suisse de Psychologie et de Psychologie Appliquée, n. 1-2, p. 9-21, 1942.

. O nascimento da inteligência na criança. 4. ed. Rio de Janeiro: Guanabara, 1987. Original em francês: La naissance de l'intelligence chez infant. Neuchatél: Delachaux et Niestlé, 1936. 1955.

. The construction of reality in the child. London: Routledge and Kegan Paul,

. The mechanisms of perception. London: Routledge and Kegan Paul, 1969. Original em francês: Les mécanismes perceptifs: modèles probabilistes, analyse génétique, relations avec l'intelligence. Paris: P.U.F., 1961.

. Biology and knowledge. Chicago and London: The University of Chicago Press, 1971. Original em francês: Biologie et connnaissance: esai sur les relations entre les regulations organiques et les processus cognitifs. Paris: Gallimard, 1967.

PIAGET, J.; DE LA HARPE, J. Immanence et transcendance: deux types d'attitudes religieuses. Genève: Association Chrétienne d'Étudiants de Suisse Romande, 1928.

PIAGET, J.; GARCIA, R. Psychogenèse et histoire des sciences. Paris: Flammarion, 1983.

VYGOTSKY, L. S. The collected works of L. S. Vygotsky: problems of general psychology. New York: Plenum, 1987. 
